Article

\title{
Improvement of the Photocatalytic Activity of ZnO/Burkeite Heterostructure Prepared by Combustion Method
}

\author{
A. Luna-Flores ${ }^{1, *} *$, M.A. Morales ${ }^{1}{ }^{(0}$, R. Agustín-Serrano ${ }^{2}$, R. Portillo ${ }^{3}$, J.A. Luna-López ${ }^{4}$, \\ G.F. Pérez-Sánchez ${ }^{5}$, A.D. Hernández-de la Luz ${ }^{4}$ (D) and N. Tepale ${ }^{1}$ \\ 1 Facultad de Ingeniería Química, Benemérita Universidad Autónoma de Puebla, Av. San Claudio y 18 sur, \\ Ciudad Universitaria, C.P. 72570, Puebla, Pue., Mexico; spinor70@yahoo.com.mx (M.A.M); \\ ntepale@hotmail.com (N.T.) \\ 2 Facultad de Ciencias Físico Matemáticas, Benemérita Universidad Autónoma de Puebla, Av. San Claudio y \\ 18 sur Ciudad Universitaria, C.P. 72570, Puebla, Pue., Mexico; ricardoagustin_s@hotmail.com \\ 3 Facultad de Ciencias Químicas, Benemérita Universidad Autónoma de Puebla, Av. San Claudio y 18 sur \\ Ciudad Universitaria, C.P. 72570, Puebla, Pue., Mexico; portilloreyes@yahoo.com \\ 4 Centro de Investigación en Dispositivos Semiconductores, Instituto de Ciencias (CIDS- ICUAP), Benemérita \\ Universidad Autónoma de Puebla, Col. Jardines de San Manuel, Av. San Claudio y 14 Sur, Cd. Universitaria, \\ Edificios IC-5 y IC-6. Puebla, Pue., 72570, Mexico; jose.luna@correo.buap.mx (J.A.L.-L.); \\ joalvada1@hotmail.com (A.D.H.-d.l.L.) \\ 5 Centro de Investigación en Fisicoquímica de Materiales del ICUAP, Benemérita Universidad Autónoma de \\ Puebla, EcoCampus Valsequillo, San Pedro Zacachimalpa, Pue, 72960, Mexico; \\ francisco.perezsanchez@correo.buap.mx \\ * Correspondence: adan.luna@correo.buap.mx
}

Received: 6 September 2019; Accepted: 26 September 2019; Published: 28 September 2019

check for updates

\begin{abstract}
In this work, a novel route is discussed to produce in one step $\mathrm{ZnO}$ /Burkeite powders by the modified solution combustion method. The $\mathrm{ZnO}$ particles enhance the photocatalytic activity in the degradation of Rhodamine B, in which Burkeite mineral acts as a support due to the pH-dependent morphology of the particle aggregates of the as-synthesized powders. The X-ray diffraction (XRD) characterization shows the presence of a heterostructure: $\mathrm{ZnO}$ /Burkeite. The Scanning Electron Microscopy (SEM) image shows a morphological dependence with the $\mathrm{pH}$ of the solution used for the synthesis. The results show that the system with the highest degradation $(92.4 \%)$ corresponds to the case in which $\mathrm{ZnO} /$ Burkeite heterostructure was synthesized with a $\mathrm{pH} 11$.
\end{abstract}

Keywords: Burkeite; ZnO; photocatalysis

\section{Introduction}

The severe environmental impact caused by climate change and pollution, as well as the dependence on non-renewable energy sources for the development of society, are part of the significant challenges for humanity [1]. Specifically, water pollution has aroused great interest in researchers; particularly heterogeneous photocatalysis has been widely used in the research about organic pollutants degradation in wastewater.

Semiconductor-based photocatalysis has already demonstrated its efficiency in terms of degradation on a wide range of organic pollutants present in water [2]; also, it can be used for air purification, $\mathrm{CO}_{2}$ reduction, $\mathrm{H}_{2}$ production, biodiesel production, and organic compounds synthesis [3,4].

Zinc oxide has been one of the most commonly used semiconductor oxides as a photocatalyst, possessing outstanding properties such as high physical and chemical stability, excellent efficiency, 
low-cost, high availability, and slight toxicity. Its primary disadvantage is that, due to its wide band gap energy ( $3.2 \mathrm{eV}$ approximately), it only activates under radiation in the UV range [5]. Further, the use of a $\mathrm{ZnO}$ suspension hinders the recovery of this photocatalyst. For this reason, many researchers propose the use of a support with characteristics such as high surface area, excellent chemical and physical stability, and that it has a role as an anchoring media [6,7].

Burkeite $\left(\mathrm{Na}_{2} \mathrm{CO}_{3} \cdot 2 \mathrm{Na}_{2} \mathrm{SO}_{4}\right)$ is a mineral with an orthorhombic crystalline phase, whose formation has been reported for temperatures higher than $100^{\circ} \mathrm{C}$ [8]. Shi et al. [9] report that one of the characteristics of Burkeite is that it tends to act as a binding agent, and under certain conditions, other inlays can be carried out with Burkeite crystals. Moreover, they show that compounds such as $\mathrm{CuSO}_{4}$ do not intervene in the crystallization process of Burkeite, some compounds that contain calcium, apparently are the unique that influence their crystallization [9].

Bonakdar et al. [10] carried out studies on the Burkeite breakage, which is a complex and friable porous material, and they propose as one of the uses of this material to be a carrier, since each Burkeite particle is an agglomerated structure with a surface coating. Several pasted crystals form these conglomerates, and the space between them originates the Burkeite's porosity structure.

The $\mathrm{ZnO}$ has been synthetized by different methods, such as hydrothermal, sol-gel, microwave assisted-hydrothermal. In general, these methods use long periods of time in their synthesis path of up

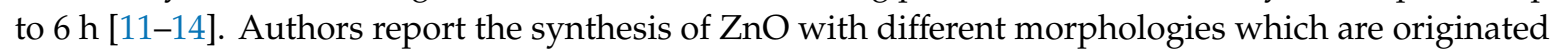
due to variations of different parameters as solvents, $\mathrm{pH}$ and temperature $[11,15,16]$ but do not report their influence in applications such as photocatalysis.

In particular, the solution combustion synthesis has the characteristic of being a simple method and uses relatively short synthesis times [17], and it has successfully been applied to obtain ZnO [18,19], to modify its surface with metals [20], and to obtain heterostructures [21]. The solution combustion synthesis employs an oxidizing compound (usually metal nitrate) and a fuel (urea, glycine, citric acid). A dependence on structural properties has been reported according to the fuel and oxidant ratio [22]. Cruz and Bulbulian proposed a modification of this method when using metal hydroxide instead of its nitrate [23].

This paper aims to report the synthesis in one step and photocatalytic activity of $\mathrm{ZnO} /$ Burkeite heterostructure powders, using the modified solution combustion method obtaining the $\mathrm{Zn}(\mathrm{OH})_{2}$ from $\mathrm{ZnSO}_{4}$ using $\mathrm{NaOH}$ as a $\mathrm{pH}$ modifier. The results show interesting optical, structural, and morphological properties of $\mathrm{ZnO} /$ Burkeite heterostructure. In addition, they show an increase in the adsorption and degradation of Rhodamine B of up to 5 times and $30 \%$, respectively, for the $\mathrm{ZnO} /$ burkeite composite compared to $\mathrm{ZnO}$. The heterostructure showing better photocatalytic activity was when the value of the $\mathrm{pH}$ corresponded to 11 in the $\mathrm{ZnO}$ precursor solution.

\section{Results and Discussion}

\subsection{XRD Analysis}

In Figure 1 the $\mathrm{X}$-ray diffractograms (XRD) for the $\mathrm{ZnO} /$ Burkeite heterostructures ( $\mathrm{ZnOS}$ ) materials and the $\mathrm{ZnO}$ are shown. The diffractograms indicate the synthesis of $\mathrm{ZnO}$ in the hexagonal phase according to the datasheet PDF 05-0664. The crystal sizes for these samples were obtained with the Scherrer equation, using the reference peak at $2 \theta=36.2$ of the $\mathrm{ZnO}$. The results reveal that as the $\mathrm{pH}$ increases, the crystal size of the $\mathrm{ZnO}$ in the powders increases too. Their corresponding values are $38.969 \mathrm{~nm}, 48.112 \mathrm{~nm}, 68.03 \mathrm{~nm}$, and $44.69 \mathrm{~nm}$ for the samples ZnOS-9, ZnOS-10, ZnOS-11, and ZnO, respectively. The number at the end of this nomenclature indicates the $\mathrm{pH}$ used during the synthesis method. It has been observed that one of the main effects of the $\mathrm{Na}^{+}$ions on the lattice parameters is the inhibition of the crystal growth of $\mathrm{ZnO}$ along the c-axis direction [24]. Such effect is evident in the samples under study because the $\mathrm{a} / \mathrm{c}$ ratio values of the $\mathrm{ZnO}$ phase depend directly upon the solution $\mathrm{pH}$, which corresponds to 1.0403, 1.6475, and 3.7043 for ZnOS-9, ZnOS-10, and ZnOS-11, respectively, while for $\mathrm{ZnO}$ the $\mathrm{a} / \mathrm{c}$ ratio is 0.62 (the peaks used to calculate the $\mathrm{a} / \mathrm{c}$ ratios were the corresponding to 
$\mathrm{ZnO}$ structure). Moreover, in Figure 1, it is verified that in all the samples the peaks labeled with solid circles belong to Burkeite (PDF 24-1134). Although there are reports about of Burkeite formation at low temperatures, the fact that the sharp peaks in the XRD appear well defined after the synthesis reaction during combustion process (where temperatures have been reached above $600{ }^{\circ} \mathrm{C}$ ) is due to the high thermal stability of such material [25]. It is proposed that the Burkeite formation is due to the presence of urea in the synthesis of $\mathrm{ZnO}$ according to the following chemical reactions:

$$
\begin{gathered}
\mathrm{ZnSO}_{4}+\mathrm{NaOH} \rightarrow \mathrm{Zn}(\mathrm{OH})_{2}+\mathrm{Na}_{2} \mathrm{SO}_{4} \\
\mathrm{Zn}(\mathrm{OH})_{2} \underset{\Delta}{\rightarrow} \mathrm{ZnO}+\mathrm{H}_{2} \mathrm{O} \\
3 \mathrm{Na}_{2} \mathrm{SO}_{4}+\mathrm{CO}\left(\mathrm{NH}_{2}\right)_{2} \underset{\Delta}{\rightarrow} \mathrm{Na}_{6}\left(\mathrm{CO}_{3}\right)\left(\mathrm{SO}_{4}\right)_{2}+\text { byproducts }
\end{gathered}
$$

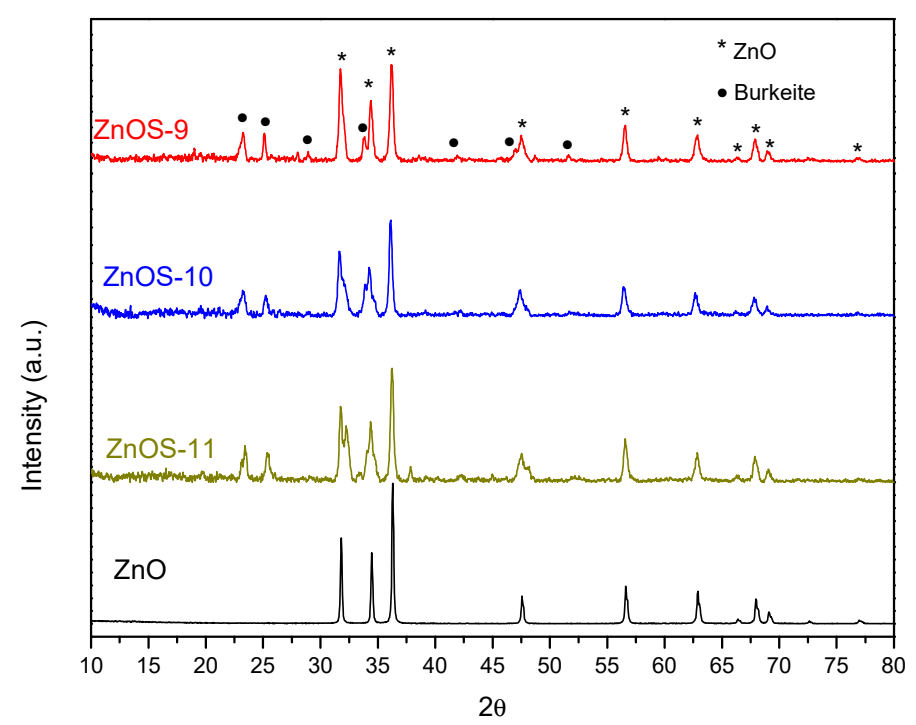

Figure 1. X-rays diffraction spectra of the as-synthesized $\mathrm{ZnO}$ and $\mathrm{ZnO}$ /Burkeite heterostructures.

\subsection{FTIR and Thermal Analysis}

In Figure 2a the FTIR spectra of the as-synthesized samples are shown. In this figure, a well-defined wide and intense peak around $1100-1080 \mathrm{~cm}^{-1}$ is observed, which is associated with the stretching and bending modes of $\mathrm{SO}^{4-}$ [26]. This peak is slightly distorted on the left-side as the $\mathrm{pH}$ is increased. The sharpest peak located around $620 \mathrm{~cm}^{-1}$ is characteristic from $\mathrm{Zn}-\mathrm{O}$ [27]. Figure $2 \mathrm{~b}$ shows the Thermogravimetric Analysis (TGA) curves from the as-synthesized samples. In all the cases are present two distinctive regions of weight reduction: the first one corresponds to the range of temperatures lower than $150^{\circ} \mathrm{C}$ in which weight lost up to $15 \%$ is observed and is associated with dehydration from the surface due to water loss adsorbed by the environment, and the second region in the range from 150 to $350^{\circ} \mathrm{C}$ is associated with the elimination of the terminal $\mathrm{OH}$ ions of the $\mathrm{ZnO}$ structure, which are preferably distributed along the c-axis of the crystalline lattice as reported before in the literature [28]. Beyond these temperatures, the weight remains practically constant. 


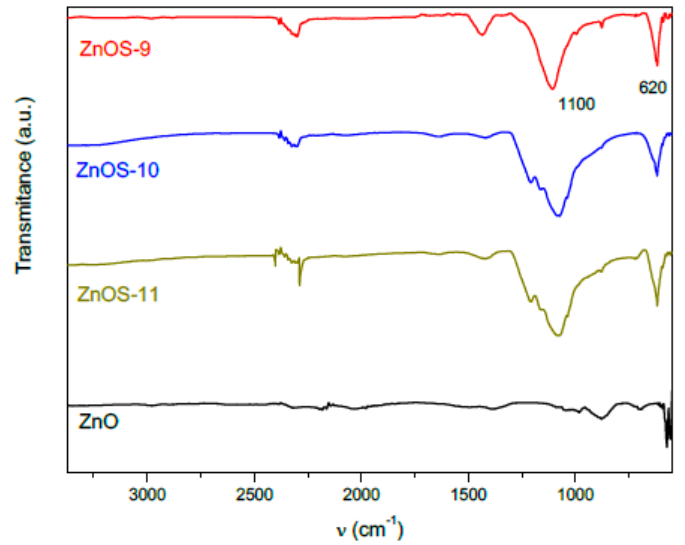

(a)

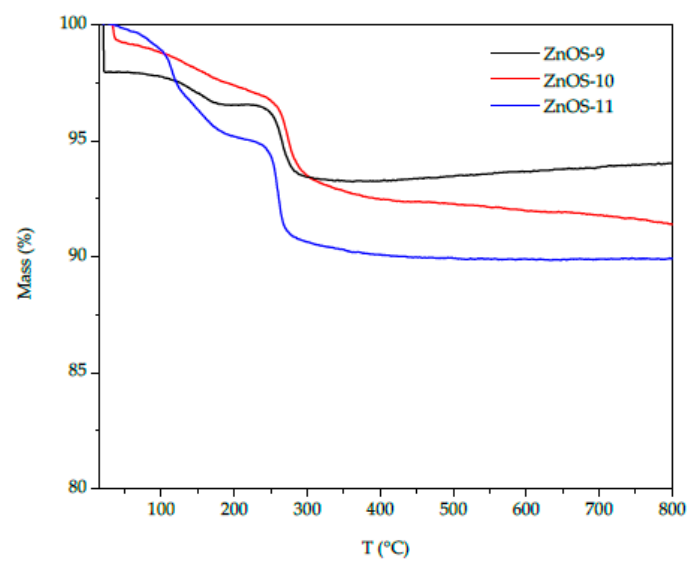

(b)

Figure 2. (a) FTIR spectra of as-synthesized ZnOS photocatalysts and ZnO, (b) TGA for the as-synthesized $\mathrm{ZnOS}$ heterostructure materials.

\subsection{SEM Analysis}

Figure 3 shows SEM images from the as-synthesized photocatalysts where the influence of $\mathrm{pH}$ on the morphology of these materials is appreciated. For the case of the ZnOS-9 (Figure 3a) sample, its morphology consists of sub-micrometric particles mixed with larger particles whose sizes are of the order of several microns. The ZnOS-10 (Figure 3b) sample shows a lesser density of sub-micrometric particles being more evident the formation of sheet-like particles whose sizes are in the range of 2-10 $\mu \mathrm{m}$. The composite ZnOS-11 (Figure 3c) sample evidences that the size of the sheet-like particles decreases giving rise to the formation of conglomerates. The $\mathrm{Na}^{+}$ions present in the solution do not allow to obtain a material with long-range crystallinity; this means that the primary nucleus of $\mathrm{ZnO}$ aggregates to form larger secondary particles varying in morphology and size, which agrees with the results reported by Becker et al. [13]. The formation of Burkeite is limited by both the amount of urea present and the temperature in the aqueous solution, expecting that its formation takes place during the first stages of combustion, adhering to the surface of the $\mathrm{ZnO}$ conglomerates. The results of the EDS measurements are included in Table 1. The atomic weight percent of $\mathrm{ZnO}$ in the composites corresponded to 32.39, 32.74, and $42.20 \mathrm{wt} \%$ for the samples ZnOS-9, ZnOS-10, and ZnOS-11, respectively. Finally, in Figure 3d we observed a spherical morphology of the ZnO particles. Therefore, we can conclude that the anchoring process on support plays a fundamental role in the final morphology of the $\mathrm{ZnO}$. 
a)

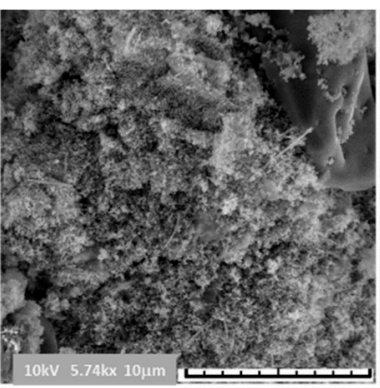

c)

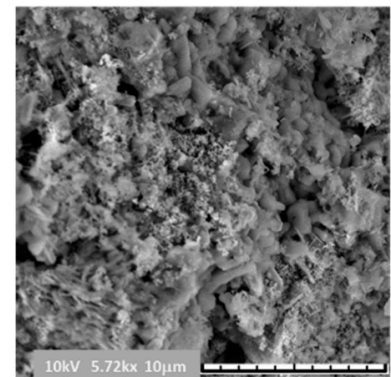

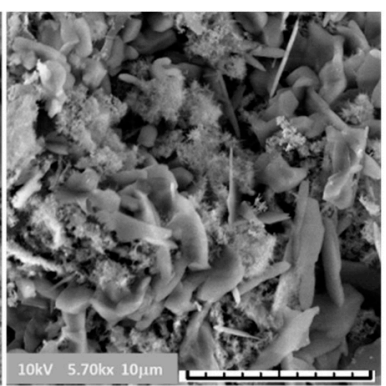

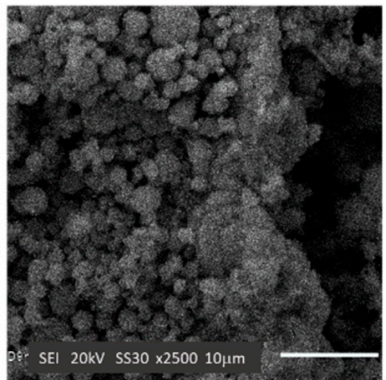

b)

d)

Figure 3. SEM images of the ZnOS samples obtained at different $\mathrm{pH}$ values. (a) ZnOS-9, (b) ZnOS-10, (c) ZnOS-11, (d) ZnO.

\subsection{Surface Area Analysis}

Table 1 summarizes the surface area values of the samples which were calculated employing Brunauer-Emmett-Teller analysis (BET). As can be seen from Table 1, $\mathrm{pH}$ plays a meaningful role on the aggregation mechanism of the $\mathrm{ZnO}$ nuclei and in the subsequent adhesion process on Burkeite, which lead to the obtaining of the $\mathrm{ZnO} /$ Burkeite heterostructure. The sample $\mathrm{ZnOS}-10$ is the one that shows the largest surface area but the smallest pore size distribution, which suggests that the $\mathrm{ZnO}$ is embedded and leaves exposed the Burkeite on the surface of the heterostructure. This scenario may be due to a structural rearrangement in the crystalline lattice of Burkeite originated by the substitution between sulfate ions and carbonate ions, causing a slight disorder in its crystalline lattice [29]. Otherwise, the BET results for the ZnOS-9 and ZnOS-11 samples corresponding to adsorption area and pore sized distribution suggest that $\mathrm{ZnO}$ is on the surface of the $\mathrm{ZnO} /$ Burkeite heterostructure that gives rise to both a reduction of BET adsorption area and a more substantial pore size value. The pore size distribution was determined by analyzing the physisorption of nitrogen gas $\left(\mathrm{N}_{2}\right)$, whose molecules are smaller than the molecules of Rhodamine B. Thus, although the $\mathrm{N}_{2}$ molecules were able to probe a larger surface area in the case of ZnOS-10, the heterogeneity in the form of interstitial pores likely limits the diffusion of the bulky molecules of the Rhodamine B into the interior of these and the amount of dye adsorbed. In this way, the distribution of the active phase may be another factor that limits the photocatalytic activity of the materials, since Rhodamine B must be adsorbed on the surface of the semiconductor $(\mathrm{ZnO})$.

Table 1. Optical, structural, and photocatalytic characteristics of the $\mathrm{ZnOS}$ composite and $\mathrm{ZnO}$.

\begin{tabular}{|c|c|c|c|c|c|c|c|c|c|c|c|c|}
\hline \multirow{2}{*}{ Sample } & \multirow{2}{*}{$\begin{array}{l}\mathrm{Eg} \\
(\mathrm{eV})\end{array}$} & \multirow{2}{*}{$\begin{array}{l}\text { BET } \\
\left(\mathrm{m}^{2} / \mathrm{g}\right)\end{array}$} & \multirow{2}{*}{$\begin{array}{l}\text { Pore } \\
\text { Size } \\
(\AA ̊)\end{array}$} & \multirow{2}{*}{$\begin{array}{l}\text { RhB } \\
\text { Abs. } \\
\text { (\%) }\end{array}$} & \multirow{2}{*}{$\begin{array}{c}\% \\
\text { Degradation } \\
\text { of RhB }\end{array}$} & \multirow{2}{*}{$\begin{array}{c}\text { Kinetic } \\
\text { Constant } \\
\mathrm{k}_{\left(\mathrm{seg}^{-1}\right)}\end{array}$} & \multicolumn{6}{|c|}{ EDS (wt $\%)$} \\
\hline & & & & & & & $\mathrm{Na}$ & C & $\mathrm{S}$ & $\mathrm{Zn}$ & O & I \\
\hline ZnOS-9 & 3.24 & 3.54 & 42.39 & 21.7 & 82.5 & 0.01988 & 23.77 & 5.07 & 10.01 & 23.52 & 37.49 & 0.14 \\
\hline ZnOS-10 & 3.27 & 48.7 & 20.5 & 6.3 & 7.3 & 0.000997 & 25.01 & 5.82 & 8.55 & 20.77 & 39.43 & 0.42 \\
\hline ZnOS-11 & 3.25 & 2.7 & 42.19 & 8.2 & 92.4 & 0.027769 & 24.24 & 8.05 & 6.81 & 22.46 & 38.44 & 0.0 \\
\hline $\mathrm{ZnO}$ & 3.11 & $21.8^{\mathrm{a}}$ & $17.1^{\mathrm{a}}$ & 4.3 & 63.8 & 0.009795 & - & - & - & 83.28 & 16.72 & - \\
\hline
\end{tabular}

a Ref [30]; I- impurities. 


\subsection{UV-Vis Analysis}

In Figure 4 UV-vis absorption spectra for the ZnOS series are shown. The results present a broad absorption band in the range of $250-400 \mathrm{~nm}$ with two significant absorption sub-bands: a left-band with a smaller intensity centered around $265 \mathrm{~nm}$, which can be associated with the Burkeite phase, and a right-band with a major intensity, which is located around $350 \mathrm{~nm}$ and associated with $\mathrm{ZnO}$. In relation to the latter, the sample $\mathrm{ZnOS}-10$ is the one with the highest absorption intensity; this means that this sample possesses a major homogeneity on the surface morphology of the sample [31], which agrees with the SEM images shown above. Finally, we observed the absorption spectra of the ZnO material. This spectrum exhibits a broad absorption band around $500 \mathrm{~nm}$ is associated with lattice defects formed by nitrogen-doping generated by combustion process [30]. The calculated band gap energies (Eg) for all samples are given in Table 1.

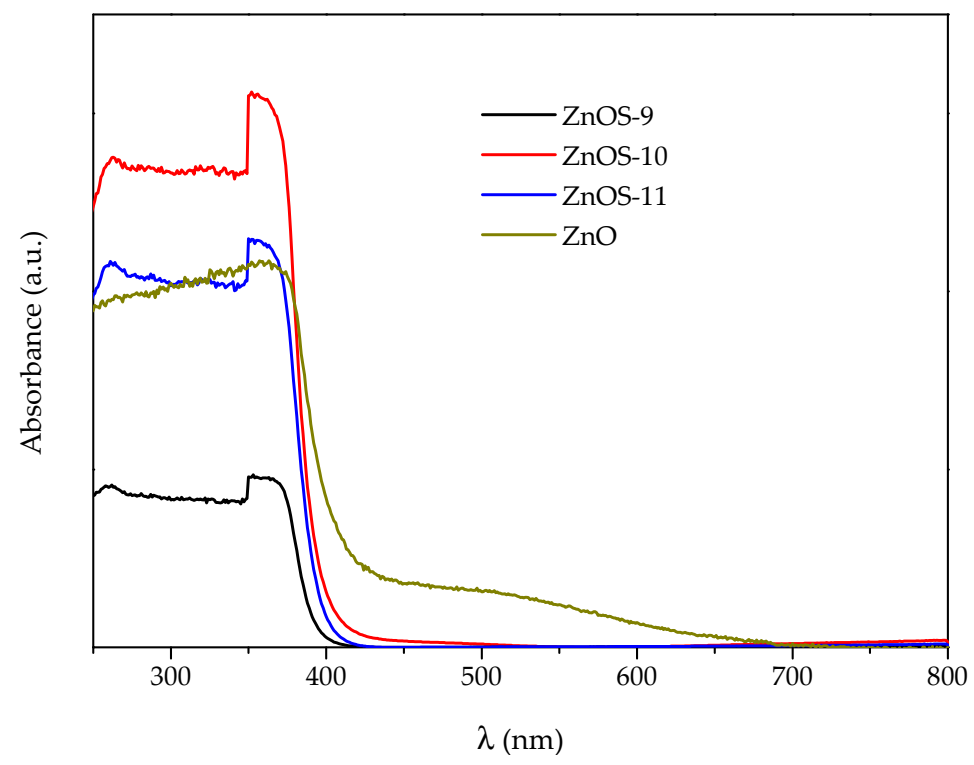

Figure 4. UV-vis absorption spectra for the as-synthesized $\mathrm{ZnOS}$ heterostructures and $\mathrm{ZnO}$.

\subsection{Degradation of Rhodamine $B$}

The first step for the photocatalytic degradation of a dye is its adsorption on the surface of the catalyst. In this case, since the intensity of the absorption peak of Rhodamine B ( $554 \mathrm{~nm}$ ) is directly related to the concentration of the solution, the amount of Rhodamine B adsorbed by the photocatalyst was calculated as the difference between the intensity of the initial concentration (Rhodamine $5 \mathrm{mg} / \mathrm{L}$ ) and the zero-time concentration (time to which the UV lamp is on). The values of adsorption percentages for the different photocatalysts are given in Table 1. The results show that the ZnOS-9 sample exhibits the highest percentage of adsorption. The high value of the adsorption percentage for ZnOS-9 composite is also associated with its morphology and pore size; moreover, we can add that this material is the one that presents the lowest percentage of weight loss in the TG analysis, which would represent the greatest purity. The above finding agrees with the results obtained by using the XRD and the BET techniques. If the sample is considered to have both a smaller crystallite size and a larger pore size, these characteristics positively impact on the dye adsorption on the surface of the photocatalyst because they give rise to the increase in the surface area of the crystallites and the easy access of the molecules within the volume of the material.

To verify whether a de-ethylation process occurs during the degradation of Rhodamine B [32], in Figure 5 are plotted the normalized UV-vis spectra evolution during the photocatalytic degradation process of Rhodamine B by exposing of the materials as-synthetized. In the case on the ZnOS-11, the weak intensity of the absorption peak indicates that the degradation process of Rhodamine B is practically completed when the exposing time corresponds to $90 \mathrm{~min}$. In Figure 5, we can 
see that the degradation process is carried out by two routes: cleavage and de-ethylation of Rhodamine B. Cleavage is the dominant mechanism at the beginning of the photocatalytic process (30-45 min). For photocatalysts as-synthesized, a shift towards $540 \mathrm{~nm}$ is observed, which indicates only the formation of the $\mathrm{N}, \mathrm{N}, \mathrm{N}^{\prime}$-triethylated Rhodamine, in accordance with results reported elsewhere [32,33]. In general, we can observe from UV-vis spectra that the longer time exposing, the weaker absorption peak.

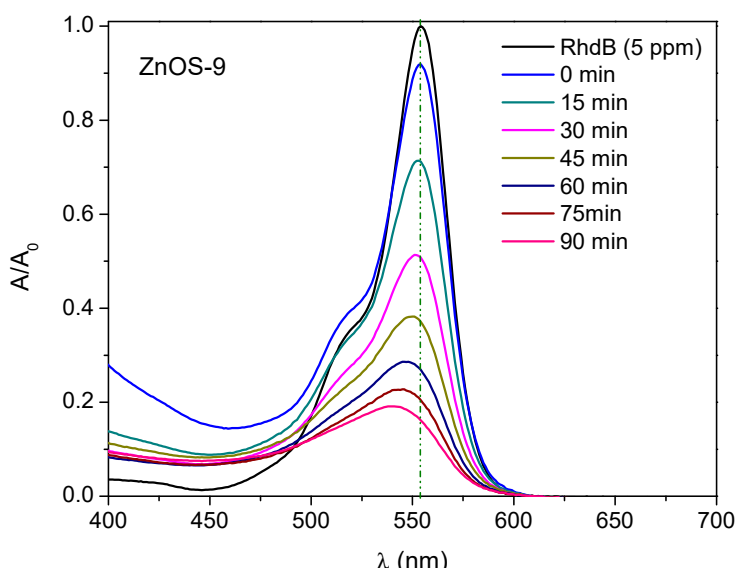

(a)

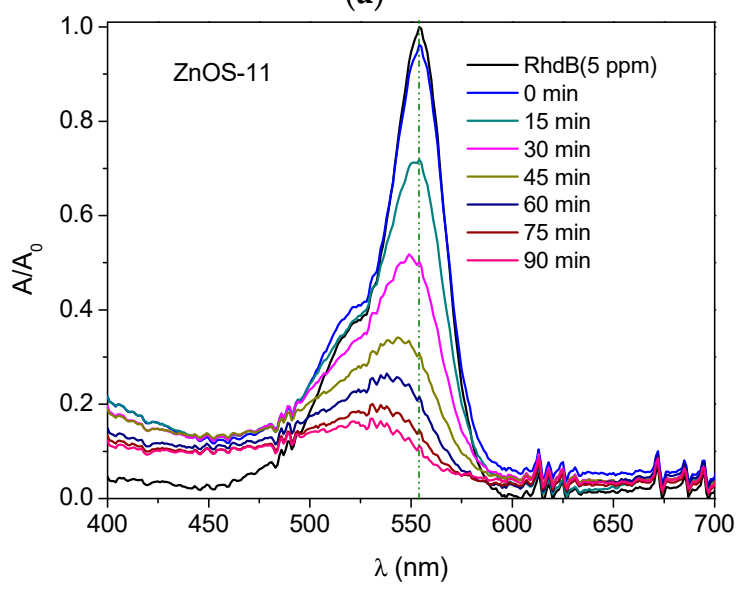

(c)

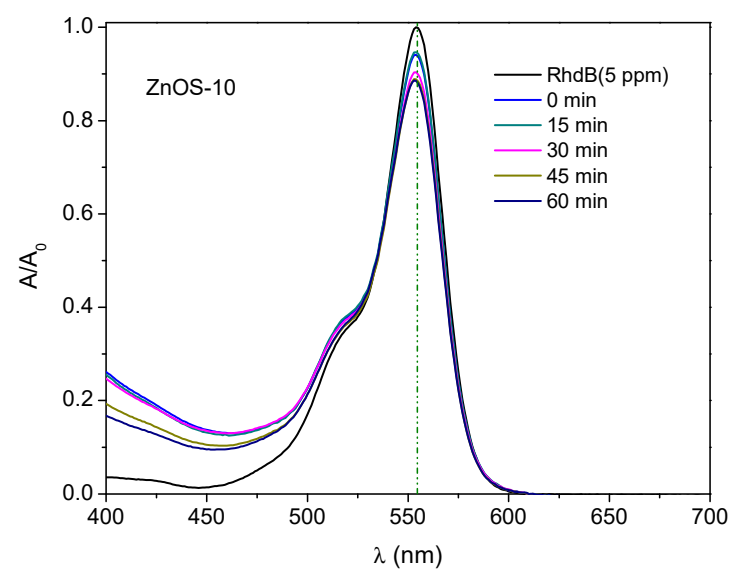

(b)

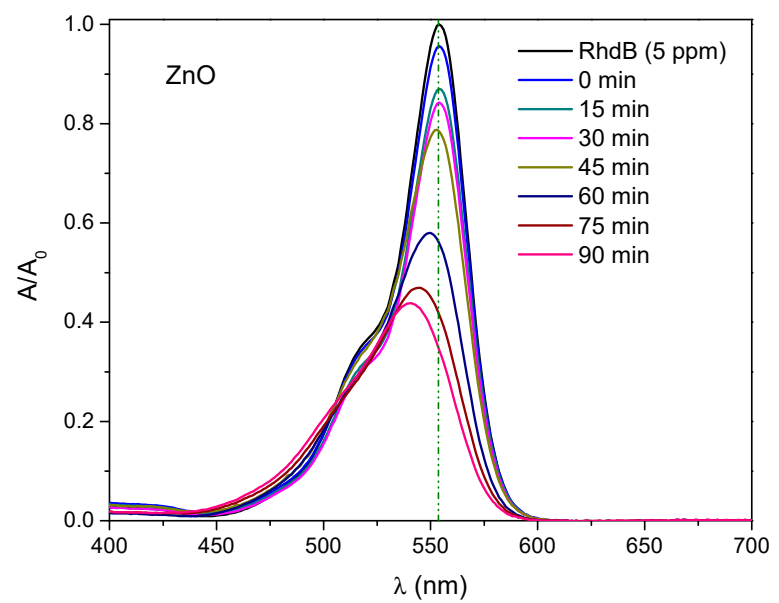

(d)

Figure 5. Normalized UV-vis spectra during the degradation of Rhodamine B for the as-synthesized ZnOS heterostructures, (a) ZnOS-9, (b) ZnOS-10, (c) ZnOS-11, and (d) ZnO.

The concentration profiles in Figure 6a represent the photocatalytic activity during the degradation of Rhodamine $\mathrm{B}$ using the $\mathrm{ZnO} /$ Burkeite heterostructures as photocatalysts. Calculation of the $\mathrm{C} / \mathrm{C}_{0}$ ratio was carried out considering the absorbance of Rhodamine $B$ at $554 \mathrm{~nm}$. In Figure 5, the absorbance used in the calculation of the $C / C_{0}$ ratio is represented by a vertical line. The photocatalyst synthesized with a $\mathrm{pH}$ of 11 (ZnOS-11) is the one that shows the highest photocatalytic activity with a degradation percentage of Rhodamine B of approximately $92 \%$ after $90 \mathrm{~min}$ of UV irradiation. The pseudo-first order kinetic constant $(\mathrm{k})$ was deduced by fitting the data obtained during the photocatalytic process and is displayed in Table 1 (see also Figure 6b). 


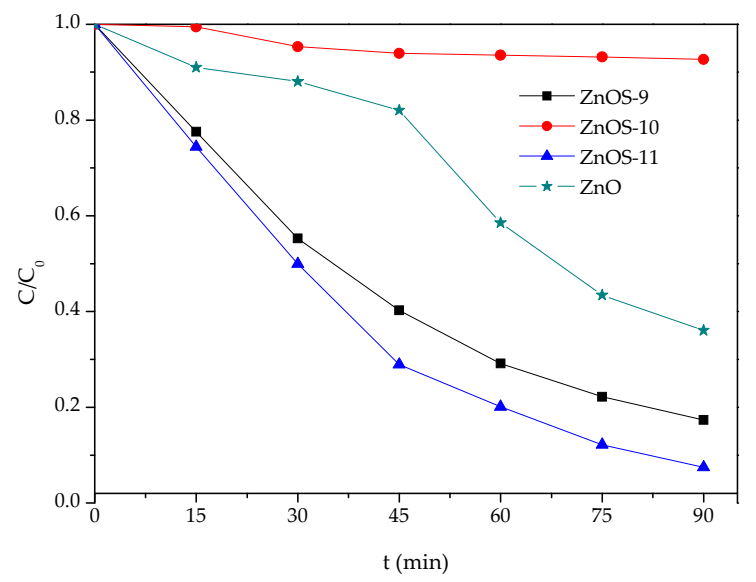

(a)

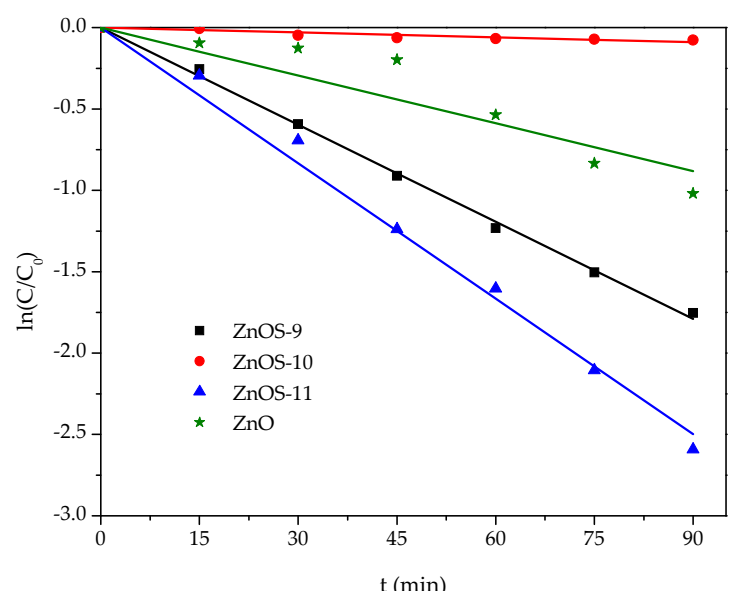

(b)

Figure 6. (a) Rhodamine B degradation rate for the different photocatalysts as-synthesized, (b) The pseudo-first order kinetic photocatalytic degradation of Rhodamine B for the ZnOS samples.

According to these results, we can establish a clear relationship between the effect of $\mathrm{pH}$ and the morphology characteristics of the $\mathrm{ZnO} /$ Burkeite heterostructure powders with the photocatalytic activity. A significant result is that for a $\mathrm{pH}$ of 10 , the lowest photocatalytic activity is obtained. As we mentioned above, the highest photocatalytic activity was achieved by a $\mathrm{pH}$ of 11 for which the $92.4 \%$ of degradation of Rhodamine B is obtained, approximately $30 \%$ more than $\mathrm{ZnO}$ photocatalyst.

This counterintuitive behavior is well known from recent studies using another type of semiconductor material [34-36] and semiconductor heterostructure-based powders $[37,38]$ where it was observed that a low surface adsorption area has a high photocatalytic activity for the Rhodamine $B$ degradation. The origin of the high photocatalytic activity is derived from semiconductor materials that exhibit the physical property known as the photoelectric effect. The latter effect allows semiconductors to absorb photons when they are exposed to UV-light, resulting in the generation of hole-electron pairs owing to the electronic transitions from the valence to conduction band; such transitions are determined by their intrinsic band gap energy. Even more, the morphology of the particles in the semiconductor powder favors the valence electrons (photocarriers) transport to their surface, which has been demonstrated in the case of silver phosphate powders when their particles have tetrahedral and cubic morphologies [39]. Therefore, this explains the morphology role of the $\mathrm{ZnO} / \mathrm{Burkeite}$ heterostructure. In the case of the ZnOS-10 sample, it inhibits the photocatalytic activity, due to the photocarriers which are inside of the same sheet morphology. Contrariwise, in the case of ZnOS-9 and ZnOS-11 samples, the photocarriers are found in the $\mathrm{ZnO}$ localized on the surface of semiconductor heterostructure with fine particles and sheets conglomerate morphologies.

\section{Materials and Methods}

\subsection{Synthesis of $\mathrm{ZnO} /$ Burkeite Heterostructure}

All reagents were used without any additional purification. The synthesis of $\mathrm{ZnO}$ was carried out as follows: in $5 \mathrm{~mL}$ of distilled water, sodium hydroxide ( $\mathrm{NaOH}$, Fermont, $98.5 \%)$ was added to obtain a $\mathrm{pH}$ of 9,10 , and 11 . Afterwards, $500 \mathrm{mg}$ of zinc sulfate $\left(\mathrm{ZnSO}_{4}\right.$, Fermont, $\left.99 \%\right)$ and $500 \mathrm{mg}$ of urea $\left(\mathrm{NH}_{2} \mathrm{CONH}_{2}\right.$, Macron, USP) were added to the solution. The solution was placed in an ultrasonic bath for 5 minutes, and then the water was evaporated at $90^{\circ} \mathrm{C}$. The resulting paste was subjected to a heat treatment at $600{ }^{\circ} \mathrm{C}$ for $15 \mathrm{~min}$ in a preheated muffle, and with this method, the $\mathrm{ZnO} /$ Burkeite heterostructure was obtained. The material synthetized was called $\mathrm{ZnOS}$; therefore, the samples labeled with the nomenclature ZnOS-9, ZnOS-10, ZnOS-11 correspond to ZnO/Burkeite material obtained at $\mathrm{pH}$ of 9,10, and 11, respectively. Moreover, for comparison purposes a sample of $\mathrm{ZnO}$ without Burkeite was prepared, following the same procedure but using $250 \mathrm{mg}$ of $\mathrm{Zn}\left(\mathrm{NO}_{3}\right)_{2}$ 
$6 \mathrm{H}_{2} \mathrm{O}$ (to ensure that Burkeite formation is not carried out) and $500 \mathrm{mg}$ of urea without the addition of $\mathrm{NaOH}$.

\subsection{Characterization and Analytical Techniques}

XRD analysis was performed using a Bruker X-ray Diffraction D6-Discover equipment (Karlsrhe, BW, Germany). The FTIR spectra were obtained using a Perkin Elmer Spectrum One spectrophotometer (Shelton, CT, USA) equipped with an ATR accessory. Thermal analysis was determined on a Netzsch Thermal Analyser model STA 449F3 Jupiter from 25 to $800^{\circ} \mathrm{C}$ under a nitrogen atmosphere. The SEM micrographs were obtained with a JSM-6610LV JEOL electron microscope (Akishima, TYO, Japan). The nitrogen adsorption analysis was carried out to determine the pore size distribution and the isotherm curve using an Autosorb 1C Quantachrome (Quantachrome, Boynton Beach, FL, USA) equipped with a Verlab VE-5600UV photometer (Quantachrome, Boynton Beach, FL, USA) and MetaSpec Pro analysis software (Quantachrome, Boynton Beach, FL, USA). Diffuse Reflectance Spectroscopy (DRS) using a Varian Cary 400 spectrophotometer with a Harrick RD accessory was used for the optical characterization of the samples.

\subsection{Degradation tests}

Degradation tests were carried out following the system developed by Luna-Flores et al. [40]. The solution to be degraded was $60 \mathrm{~mL}$ of Rhodamine B (5 mg/L) with $250 \mathrm{mg} / \mathrm{L}$ of the photocatalyst. Once the photocatalyst was dispersed in the solution, it was kept in darkness for $15 \mathrm{~min}$ to establish the adsorption-desorption equilibrium. After $15 \mathrm{~min}$, the suspension was irradiated with UV light $(20 \mathrm{~W}, 365-465 \mathrm{~nm})$. The degradation monitoring of Rhodamine B was carried out employing the UV-vis spectroscopy, taking aliquots every $15 \mathrm{~min}$.

\section{Conclusions}

A simple methodology has been proposed for the synthesis in one step of $\mathrm{ZnO} /$ Burkeite heterostructures by the modified solution combustion method. This approach allows tailoring the structural and morphological properties of the photocatalyst to optimize its photocatalytic activity in the degradation of Rhodamine B. Moreover, it has been shown that the optimal synthesis condition for the synthesis of $\mathrm{ZnO} /$ Burkeite heterostructure with higher photocatalytic activity corresponds to a $\mathrm{pH}$ value in the solution of 11 . Thus, the improvement in the degradation process of Rhodamine $B$ depends on the $\mathrm{pH}$-dependent morphological properties of the $\mathrm{ZnO}$ particles anchored on the surface of the support, which in turn, showed better structural properties (grain size) and larger pore sizes.

Author Contributions: Conceptualization, A.L.-F.; formal analysis, A.L.-F., M.A.M., R.A.-S., R.P., and G.F.P.-S.; writing-original draft preparation, A.L.-F. and M.A.M.; writing-review and editing, G.F.P-S., J.A.L.-L., A.D.H.-d.1.L., N.T.

Funding: This research received no external funding.

Conflicts of Interest: The authors declare no conflict of interest.

\section{References}

1. Hutton, F.G.; Feulner, G.; Lund, P.D.; Henson, S.; Røttingen, J.-A.; Hoffman, S.J.; Butler, D. Global Challenges: An innovative journal for tackling humanity's major challenges. Glob. Chall. 2017, 1, 3-4. [CrossRef]

2. Ajmal, A.; Majeed, I.; Malik, R.N.; Idriss, H.; Nadeem, M.A. Principles and mechanisms of photocatalytic dye degradation on $\mathrm{TiO}_{2}$ based photocatalysts: A comparative overview. RSC Adv. 2014, 4, 37003-37026. [CrossRef]

3. Yuan, J.; Liu, L.; Guo, R.-R.; Zeng, S.; Wang, H.; Lu, J.-X. Electroreduction of $\mathrm{CO}_{2}$ into Ethanol over an Active Catalyst: Copper Supported on Titania. Catalysts 2017, 7, 220. [CrossRef] 
4. Thakur, R.S.; Chaudhary, R.; Singh, C. Fundamentals and applications of the photocatalytic treatment for the removal of industrial organic pollutants and effects of operational parameters: A review. J. Renew. Sustain. Energy 2010, 2, 042701. [CrossRef]

5. Kumar, S.G.; Koteswara Rao, S.R. Zinc oxide based photocatalysis: Tailoring surfacebulk structure and related interfacial charge carrier dynamics for better environmental applications. RSC Adv. 2015, 5, 3306-3351. [CrossRef]

6. Srikanth, B.; Goutham, R.; Badri Narayan, R.; Ramprasath, A.; Gopinath, K.P.; Sankaranarayanan, A.R. Recent advancements in supporting materials for immobilized photocatalytic applications in waste water treatment. J. Environ. Manag. 2017, 200, 60-78. [CrossRef] [PubMed]

7. Hanaor, D.A.H.; Sorrell, C.C. Sand Supported Mixed-Phase TiO2 Photocatalysts for Water Decontamination Applications. Adv. Eng. Mater. 2014, 16, 248-254. [CrossRef]

8. Korsakov, A.V.; Golovin, A.V.; De Gussem, K.; Sharygin, I.S.; Vandenabeele, P. First finding of burkeite in melt inclusions in olivine from sheared lherzolite xenoliths. Spectrochim. Acta Part A 2009, 73, 424-427. [CrossRef]

9. Shi, B.; Frederick, W.J., Jr.; Rousseau, R.W. Effects of Calcium and Other Ionic Impurities on the Primary Nucleation of Burkeite. Ind. Eng. Chem. Res. 2003, 42, 2861-2869. [CrossRef]

10. Bonakdar, T.; Ghadiri, M.; Ahmadiam, H.; de Juan, M.L.; Xu, D.; Tantawy, H.; Smith, D. Impact attrition of spray-dried burkeite particles. Powder Technol. 2016, 304, 2-7. [CrossRef]

11. Alias, S.S.; Ismail, A.B.; Mohamad, A.A. Effect of $\mathrm{pH}$ on $\mathrm{ZnO}$ nanoparticle properties synthesized by sol-gel centrifugation. J. Alloy. Compd. 2010, 499, 231-237. [CrossRef]

12. Zhang, J.; Sun, L.; Yin, J.; Su, H.; Liao, C.; Yan, C. Control of ZnO Morphology via a Simple Solution Route. Chem. Mater. 2002, 14, 4172-4177. [CrossRef]

13. Becker, J.; Raghupathi, K.R.; St. Pierre, J.; Zhao, D.; Koodali, R.T. Tuning of the Crystallite and Particle Sizes of ZnO Nanocrystalline Materials in Solvothermal Synthesis and Their Photocatalytic Activity for Dye Degradation. J. Phys. Chem. C 2011, 115, 13844-13850. [CrossRef]

14. Cho, S.; Jung, S.-H.; Lee, K.-H. Morphology-Controlled Growth of ZnO Nanostructures Using Microwave Irradiation: From Basic to Complex Structures. J. Phys. Chem. C 2008, 112, 12769-12776. [CrossRef]

15. Huang, W.; Jia, J.; Zhou, X.; Lin, Y. Morphology controllable synthesis of ZnO crystals-pH-dependent growth. Mater. Chem. Phys. 2010, 123, 104-108. [CrossRef]

16. Amin, G.; Asif, M.H.; Zainelabdin, A.; Zaman, S.; Nur, O.; Willander, M. Influence of pH, Precursor Concentration, Growth Time, and Temperature on the Morphology of ZnO Nanostructures Grown by the Hydrothermal Method. J. Nanomater. 2011, 2011, 269692. [CrossRef]

17. Li, F.-T.; Ran, J.; Jaroniec, M.; Qiao, S.Z. Solution combustion synthesis of metal oxide nanomaterials for energy storage and conversion. Nanoscale 2015, 7, 17590-17610. [CrossRef] [PubMed]

18. Reddy, A.J.; Kokila, M.K.; Nagabhushana, H.; Rao, J.L.; Shivakumara, C.; Nagabhushana, B.M.; Chakradhar, R.S. Combustion synthesis, characterization and Raman studies of ZnO nanopowders. Spectrochim. Acta Part A 2011, 81, 53-58. [CrossRef]

19. Nagaraja, R.; Kottam, N.; Girija, C.; Nagabhushana, B.M. Photocatalytic degradation of Rhodamine B dye under UV/solar light using $\mathrm{ZnO}$ nanopowder synthesized by solution combustion route. Powder Technol. 2012, 215, 91-97. [CrossRef]

20. Cai, Y.; Fan, H.; Xu, M.; Li, Q. Rapid photocatalytic activity and honeycomb Ag/ZnO heterostructures via solution combustion synthesis. Colloids Surf. A 2013, 436, 787-795. [CrossRef]

21. Schuyten, S.; Dinka, P.; Mukasyan, A.S.; Wolf, E. A Novel Combustion Synthesis Preparation of $\mathrm{CuO} / \mathrm{ZnO} / \mathrm{ZrO} / \mathrm{Pd}$ for Oxidative Hydrogen Production from Methanol. Catal. Lett. 2008, 121, 189-198. [CrossRef]

22. Srinatha, N.; Kumar, V.D.; Nair, K.G.; Angadi, B. The effect of fuel and fuel-oxidizer combinations on ZnO nanoparticles synthesized by solution combustion technique. Adv. Powder Technol. 2015, 26, 1355-1363. [CrossRef]

23. Cruz, D.; Bulbulian, S. Synthesis of $\mathrm{Li}_{4} \mathrm{SiO}_{4}$ by a Modified Combustion Method. J. Am. Ceram. Soc. 2005, 88, 720-1724. [CrossRef]

24. Søndergaard, M.; Bøjesen, E.D.; Christensen, M.; Iversen, B.B. Size and Morphology Dependence of ZnO Nanoparticles Synthesized by a Fast Continuous Flow Hydrothermal Method. Cryst. Growth Des. 2011, 11, 4027-4033. [CrossRef] 
25. Bayuadri, C.; Verril, C.L.; Rousseau, R.W. Stability of Sodium Sulfate Dicarbonate $\left(\sim 2 \mathrm{Na}_{2} \mathrm{CO}_{3} \cdot \mathrm{Na}_{2} \mathrm{SO}_{4}\right)$ Crystals Obtained from Evaporation of Aqueous Solutions of $\mathrm{Na}_{2} \mathrm{CO}_{3}$ and $\mathrm{Na}_{2} \mathrm{SO}_{4}$. Ind. Eng. Chem. Res. 2006, 45, 7144-7150. [CrossRef]

26. Wang, L.; Liu, G.; Zou, L.; Xue, D. Phase evolution from rod-like ZnO to plate-like zinc hydroxysulfate during electrochemical deposition. J. Alloy. Compd. 2010, 493, 471-475. [CrossRef]

27. Senthilkumar, K.; Tokunaga, M.; Okamoto, H.; Senthilkumar, O.; Fujita, Y. Hydrogen related defect complexes in ZnO nanoparticles. Appl. Phys. Lett. 2010, 97, 091907. [CrossRef]

28. De la Rosa, E.; Sepúlveda-Guzman, S.; Reeja-Jayan, B.; Torres, A.; Salas, P.; Elizondo, N.; Jose Yacaman, M. Controlling the Growth and Luminescense Properties of Well-Faceted ZnO Nanorods. J. Phys. Chem. C 2007, 111, 8489-8495. [CrossRef]

29. Shi, B.; Rousseau, R.W. Structure of Burkeite and a New Crystalline Species Obtained from Solutions of Sodium Carbonate and Sodium Sulfate. J. Phys. Chem. B 2003, 107, 6932-6937. [CrossRef]

30. Ramachandran, S.; Sivasamy, A. Synthesis and characterization of nanocrystalline N-doped semiconductor metal oxide and its visible photocatalytic activity in the degradation of an organic dye. J. Environ. Chem. Eng. 2018, 6, 3770-3779. [CrossRef]

31. Khan, M.F.; Ansari, A.H.; Hameedullah, M.; Ahmad, E.; Husain, F.M.; Zia, Q.; Baig, U.; Zaheer, M.R.; Alam, M.M.; Khan, A.M.; et al. Sol-gel synthesis of thorn-like ZnO nanoparticles endorsing mechanical stirring effect and their antimicrobial activities: Potential role as nano-antibiotics. Sci. Rep. 2016, 6, 27689. [CrossRef] [PubMed]

32. Pica, M.; Calzuola, S.; Donnadio, A.; Gentili, P.L.; Nocchetti, M.; Casciola, M. De-Ethylation and Cleavage of Rhodamine B by a Zirconium Phosphate/Silver Bromide Composite Photocatalyst. Catalysts 2019, 9, 3. [CrossRef]

33. Wu, T.; Liu, G.; Zhao, J.; Hidaka, H.; Serpone, N. Photoassisted degradation of dye pollutants. V. Selfphotosensitized oxidative transformation of Rhodamine $\mathrm{B}$ under visible light irradiation in aqueous $\mathrm{TiO}_{2}$ dispersions. J. Phys. Chem. B 1998, 102, 5845-5851. [CrossRef]

34. Bi, Y.; Ouyang, S.; Umezawa, N.; Cao, J.; Ye, J. Facet effect of single-crystalline $\mathrm{Ag}_{3} \mathrm{PO}_{4}$ sub-microcrystals on photocatalytic properties. J. Am. Chem. Soc. 2011, 133, 6490-6492. [CrossRef] [PubMed]

35. Jiao, Z.; Zhang, Y.; Yu, H.; Lu, G.; Yeb, J.; Bi, Y. Concave trisoctahedral $\mathrm{Ag}_{3} \mathrm{PO}_{4}$ microcrystals with high-index facets and enhanced photocatalytic properties. Chem. Commun. 2013, 49, 636-638. [CrossRef] [PubMed]

36. Morales, M.A.; Fernández-Cervantes, I.; Agustín-Serrano, R.; Ruíz-Salgado, S.; Sampedro, M.P.; Varela-Caselis, J.L.; Portillo, R.; Rubio, E. $\mathrm{Ag}_{3} \mathrm{PO}_{4}$ microcrystals with complex polyhedral morphologies diversity obtained by microwave-hydrothermal synthesis for MB degradation under sunlight. Results Phys. 2019, 12, 1344-1356. [CrossRef]

37. Bi, Y.; Hu, H.; Ouyang, S.; Jiao, Z.; Lu, G.; Ye, J. Selective growth of metallic Ag nanocrystals on $\mathrm{Ag}_{3} \mathrm{PO}_{4}$ submicro-cubes for photocatalytic applications. Chem. Eur. J. 2012, 18, 14272-14275. [CrossRef] [PubMed]

38. Wu, Q.; Wang, P.; Niu, F.; Huang, C.; Li, Y.; Yao, W. A novel molecular sieve supporting material for enhancing activity and stability of $\mathrm{Ag}_{3} \mathrm{PO}_{4}$ photocatalyst. Appl. Surf. Sci. 2016, 378, 552-563. [CrossRef]

39. Kim, S.; Wang, Y.; Zhu, M.; Fujitsuka, M.; Majima, T. Facet Effects of $\mathrm{Ag}_{3} \mathrm{PO}_{4}$ on Charge-Carrier Dynamics: Trade-Off between Photocatalytic Activity and Charge-Carrier Lifetime. Chem. Eur. J. 2018, 24, 14928-14932. [CrossRef]

40. Luna-Flores, A.; Valenzuela, M.A.; Luna-López, J.A.; Hernández de la Luz, A.D.; Muñoz-Arenas, L.C.; Méndez-Hernández, M.; Sosa-Sánchez, J.L. Synergetic Enhancement of the Photocatalytic Activity of $\mathrm{TiO}_{2}$ with Visible Light by Sensitization Using a Novel Push-Pull Zinc Phthalocyanine. Int. J. Photoenergy 2017, 2017, 1604753. [CrossRef]

(C) 2019 by the authors. Licensee MDPI, Basel, Switzerland. This article is an open access article distributed under the terms and conditions of the Creative Commons Attribution (CC BY) license (http://creativecommons.org/licenses/by/4.0/). 